\title{
Cuidados Paternos nos Primeiros Três Anos de Vida de seus Filhos: Um Estudo Longitudinal
}

\author{
Karla da Costa Seabra* \& Maria Lucia Seidl-de-Moura \\ Universidade do Estado do Rio de Janeiro, Rio de Janeiro, Brasil
}

\begin{abstract}
RESUMO
Este trabalho investigou aspectos do envolvimento paterno tendo como base teórica a abordagem sociocultural. Participaram da pesquisa sete famílias quando seus filhos primogênitos estavam com 5 , 20 e 36 meses. As mães responderam o instrumento Estilo Paterno e foi realizada uma entrevista com os pais para investigar o nível de satisfação paterno e materno com o envolvimento do pai com os filhos e identificando em que aspectos essa participação é mais ou menos frequente. Os resultados encontrados afastam esse grupo de pais das características da paternidade tradicional. Percebe-se uma tendência de envolvimento do pai no cotidiano dos filhos, tanto nos aspectos de lazer como nos de cuidado, e um aumento dessa participação juntamente com o aumento da idade dos filhos.
\end{abstract}

Palavras-chave: paternidade; participação paterna; estilo paterno.

\begin{abstract}
Paternal Care During The First Three Years Of Age Of Their Children: A Longitudinal Study

This study investigated aspects of father involvement based on a socio-cultural approach. Seven families and their firstborn children at ages of five, twenty and thirty-six months took part in the study. The mothers answered the instrument Paternal Style and the fathers were interviewed. The aim of this work was to investigate the paternal and maternal satisfaction level of fathers' involvement with their children and to identify in which aspects the paternal participation is more or less frequent. The results indicate that these parents deviate from the characteristics of traditional fatherhood. A tendency of father involvement in the daily activities of their children was observed, both in moments of leisure and in moments of taking care of their kids, and an increase in this participation as the children got older.

Keywords: parenthood; paternal participation; parental style.
\end{abstract}

Este estudo parte do pressuposto que a família é o primeiro ambiente socializador da criança, e que o seu desenvolvimento, em amplo aspecto, depende de um "outro social" e das práticas de seus cuidadores. Acredita-se que os bebês apresentam características universais, que o investimento parental é uma característica da espécie, que as interações são constitutivas do desenvolvimento e que todos esses aspectos estão envolvidos em um contexto sociocultural (Keller, 2002; Lightfoot \& Valsiner, 1992; Seidl de Moura, 2009).

Desta forma, o desenvolvimento inicialmente depende de um parceiro que irá inserir a criança num conjunto de práticas culturais. Uma forte relação afetiva se estabelece entre a criança e o adulto, que é neste momento o seu mediador com o mundo. É através da família que, na cultura ocidental, se aprende a perceber o mundo e até situar-se nele. $\mathrm{O}$ desenvolvimento humano ocorre a partir das interações cotidianas e tanto o investimento parental como as práticas educativas, vão se regulando com o desenvolvimento da criança. Sendo assim, os pais são co-construtores do desenvolvimento de seus filhos, ao mesmo tempo em que, pela interação com eles, constituem-se como pais. Partindo desses pressupostos será realizada uma reflexão sobre as mudanças nos papéis parentais exigidas pelo sistema econômico da sociedade urbana ocidental contemporânea.

A partir da segunda metade do século XX a mulher entrou gradativamente no mercado de trabalho, chegando ao final do século buscando cada vez mais por seu desenvolvimento profissional. Segundo Keller (1998), nas mais divergentes culturas são as mães as figuras

* Endereço para correspondência: Karla da Costa Seabra: seabrakc@uol.com.br 
primárias socialmente significantes durante os meses iniciais de vida, mas diversos estudos têm mostrado a importância paterna no desenvolvimento da criança (e.g., Burdon, 1998; Cabrera, Tamis-LeMonda, Bradley, Hofferth, \& Lamb, 2000; Featherstone, 2001). Em muitas partes do mundo os pais estão mais participativos no cuidado e educação de seus filhos (e.g., Brandth \& Kvande, 2002; Dienhart, 2001; Levy-Shiff \& Israelashvili, 1988). Estas mudanças estão relacionadas a um apelo constante das mulheres para que os homens compartilhassem tarefas que, tradicionalmente, haviam sido divididas em nossa cultura assim: homem provedor/mulher cuidadora.

A pluralidade de formas conjugais e familiares, com as quais convivemos nos dias atuais, já tinha sido pontuada nos estudo de Diniz (1999) e outros mais recentes (Souza, Wagner, Branco, \& Reichert, 2007; Wagner \& Levandowski, 2008) a reafirmaram. Diniz aponta que esta variação familiar está relacionada à forma de inserção da mulher no mercado de trabalho, classificando três tipos de arranjos familiares: O primeiro seria o tradicional, no qual a mulher não exerce atividade remunerada. Na segunda classificação temos os casais em que a mulher tem um trabalho remunerado no próprio ambiente doméstico ou trabalha fora em tempo parcial, conciliando seu trabalho remunerado com os afazeres do lar e com os filhos. No último arranjo familiar, ambos os cônjuges exercem atividades remuneradas em tempo integral, podendo esse arranjo ser subdividido em: casais de duplo-trabalho (ambos trabalham em tempo integral e não necessitam de investimento fora do horário de trabalho), casais de dupla-carreira (ambos exercem atividades que exigem investimentos constantes fora do horário de trabalho) e casais mistos (apenas um cônjuge está envolvido com uma carreira e o outro com um trabalho). Esta classificação não engloba configurações monoparentais, refere-se apenas às famílias em que pai e mãe vivem juntos.

Os estudos sobre os casais de dupla-carreira (Souza e cols. 2007; Wagner \& Levandowski, 2008) têm indicado que, para este último tipo de casal, é necessária a administração de múltiplos papéis sociais, tarefas e responsabilidades, levando a uma divisão maior das atividades do lar e, consequentemente, a um aumento da participação dos homens nessas tarefas. A pesquisa de Silva e Piccinini (2007) aponta para o fato de que alguns homens demonstram dificuldade no envolvimento cotidiano com os filhos devido à demanda de trabalho e, portanto, a paternidade considerada por eles como ideal se distancia da real.
Percebe-se que a mídia no Brasil tem apoiado a transformação nos papéis materno e paterno com propagandas comerciais, e slogans do tipo "não basta ser pai, tem que participar". Santos (2004), no entanto, encontrou resultados diferentes, realizando uma análise das características masculinas representadas em duas revistas (Pais e filhos, e Crescer em família) voltadas para os cuidados, comportamentos e desenvolvimento infantil. Grande parte dos artigos é voltada às mães. $\mathrm{O}$ mesmo ocorre em relação às imagens de adultos com crianças: mais da metade representavam mulheres/mães, enquanto $25 \%$, homens/pais e $25 \%$, ambos. Na maioria das imagens paternas, os homens estão jogando, brincando, passeando ou acariciando os filhos. São raras as imagens nas quais os pais estão realizando tarefas de cuidado. Há vários exemplos de mães que abandonaram suas vidas profissionais para cuidar dos filhos e, nos artigos que envolvem quem deverá ficar com o bebê após o fím da licença maternidade, o pai não é citado.

No Brasil, estudos sobre a divisão de papéis e funções desempenhados por pais e mães têm sido realizados nos últimos anos (Fleck \& Wagner, 2003; Goetz \& Vieira, 2009; Seabra, 2007; Wagner, Predebon, Mosmann, \& Verza, 2005). Os resultados desses estudos indicam que o exercício da disciplina, o suporte afetivo, a educação básica em termos de higiene, o compromisso com a escola e o sustento econômico são compartilhados pelos progenitores. Algumas tarefas, contudo, ainda aparecem como trabalho feminino, retomando os papéis tradicionais, tais como: nutrição e o acompanhamento do cotidiano dos filhos.

Bandeira (2009), investigando as crenças de pais e mães do estado do Rio de Janeiro sobre investimento parental, encontrou resultados diferentes. Ambos valorizam, em primeiro lugar, o investimento emocional (envolvimento afetivo) com os filhos. Em seguida, as mães destacam o investimento intelectual, o socialespiritual, o familiar-pessoal, o financeiro e, por último, os cuidados básicos. Os pais destacaram, em seguida, o investimento intelectual, o social-espiritual, o familiar-pessoal, os cuidados e, por fim, o financeiro. Os aspectos menos valorizados - cuidados para as mães e financeiro para os pais - estão relacionados aos papéis tradicionais, ou seja, estas famílias afastam-se da visão clássica. Os resultados indicam uma maior preocupação com os cuidados básicos por parte dos pais, embora estes ainda sejam realizados mais intensamente pelas mães. Estes resultados corroboram os estudos de Silva e Piccinini (2007), nos quais o envolvimento paterno não se restringe ao envolvimento financeiro e ao lazer. 
Os estudos de Fleck e Wagner (2003) e RochaCoutinho (2003) com famílias brasileiras de nível socioeconômico médio em que a mulher é a principal responsável pelo provento familiar, trouxeram resultados indicando que as mulheres assumem quase totalmente a responsabilidade pelas tarefas domésticas. Ou seja, ainda que o sustento familiar não seja tradicional, o funcionamento da família ainda é clássico e a participação do marido é percebida como ajuda. Trindade, Andrade e Souza (1997) discutem ainda a relação entre o nível de escolaridade e as funções materna e paterna. O aumento da escolaridade dos pais reflete em uma diminuição da dicotomia entre as duas funções. A mãe não é a responsável exclusiva pelos cuidados com a casa e tarefas do dia a dia e o pai não é o provedor principal do lar. Discutem também que, quanto maior o nível de escolaridade dos pais, mais visível são o afeto e o estabelecimento de um relacionamento positivo entre pai e filho.

Em estudo de Bustamante e Bonfim (2005) com camadas populares em uma capital nordestina, foram apontadas três dimensões da participação paterna no cuidado com os filhos em famílias: educação (participação paterna fundamental); cuidados corporais, (atribuição feminina); e a preservação da integridade (dever de todos os membros da família). Seus resultados mostram que os papéis estão divididos nas camadas populares a partir de uma divisão sexual do trabalho. $\mathrm{O}$ homem ainda é responsabilizado pela autoridade moral e respeitabilidade familiar e a mulher tem a autoridade de manter a unidade do grupo. Na pesquisa de Souza e cols. (2007) sobre casais com dupla carreira, os cuidados com os filhos e os trabalhos domésticos também surgiram como atribuições tipicamente femininas para algumas famílias.

Outros estudos (Bittman, 1995; Gunter \& Gunter, 1990) também confirmam que a participação masculina geralmente envolve o lazer e tem início e fim predeterminados. As mulheres dedicam-se a tarefas mais cotidianas, como cuidar e educar os filhos e outras atividades domésticas. Jablonski (1999), na década de noventa, já indicava que a interação dos pais com os filhos tinha uma base mais física e lúdica, enquanto as mães centravam-se na proteção e na afetividade.

Seabra, Sivieiro e Seidl de Moura (2001) investigaram a percepção de mães primíparas de classe social média e baixa sobre o pai de seus bebês, em comparação com o que consideram como pai ideal. Apesar das transformações que os papéis materno e paterno têm sofrido nas últimas décadas, perceberam que ainda há uma tendência significativa na divisão de tarefas entre os pais, segundo a percepção das mulheres. Às mães caberiam principalmente as atividades relacionadas ao conforto físico e, aos pais, a socialização e o estabelecimento de regras, embora, segundo o relato das mães, os pais estão começando a participar deste cuidado de uma forma geral com seus filhos. Foi identificada também uma ambivalência materna em relação à participação dos pais. Ao mesmo tempo em que desejam uma maior participação em algumas atividades (ex. dar banho, alimentar, entre outras), algumas mães consideram que, em outras atividades (brincar e interagir), há uma participação excessiva dos pais de seus bebês.

Percebe-se nos estudos acima que existe uma nova "cultura de paternidade". Ainda que alguns resultados confirmem diferenças na participação do pai relacionadas às condições de trabalho do casal e do nível socioeconômico, o pai parece mais presente na responsabilidade pela criação conjunta dos filhos, mostrando-se mais disponível e envolvido nas tarefas do cotidiano.

Falar do exercício da paternidade é pensar que se inicia desde a gestação e nascimento do filho. Em alguns casos isto se dá até anteriormente, através do próprio desejo ou não de se tornar pai e de suas experiências de vida. Em relação à participação paterna durante a gestação, Piccinini, Silva, Gonçalves, Lopes e Tudge (2004) desenvolveram um trabalho cujo objetivo era investigar como ocorre o envolvimento paterno durante o terceiro trimestre de gestação, acreditando que o período da gravidez exige adaptações por parte do pai, no que concerne aos novos papéis que deverá assumir. Verificaram um envolvimento expressivo dos pais na gestação nos aspectos emocionais e comportamentais. Isso revela modificações quanto à paternidade no período da gestação, que parece não se encontrar mais restrita ao universo feminino na maioria dos casais investigados. Contudo, alguns pais também demonstraram dificuldade de maior participação e envolvimento. Na verdade, mesmo os pais mais envolvidos durante a gestação relataram algumas restrições quanto à sua participação. A grande maioria dos pais não manifestou o desejo de assistir ao parto, ou evidenciaram interesse de buscar conhecimentos sobre o desenvolvimento do bebê, demonstrando que o envolvimento paterno na gravidez ainda encontra barreiras que poderão implicar a falta de um envolvimento mais ativo após o nascimento do bebê.

Para Silva e Piccinini (2007) a participação dos pais tende a aumentar juntamente com o crescimento dos filhos. Já para Jablonski (1998) apesar das atitu- 
des igualitárias, a divisão de trabalhos dentro do lar vai ficando mais estereotipada e tradicional com o crescimento dos filhos. É possível perceber, nestes estudos, alguma diferença na participação paterna no cotidiano com os filhos de acordo com a idade e sexo dos mesmos. Por exemplo, é comum o pai acompanhar o filho nas aulas de futebol, mas o mesmo não tende a acontecer com a filha nas aulas de ballet. Assim como durante a fase de amamentação o pai fica privado de uma participação mais direta com o bebê neste contexto.

A paternidade contemporânea foi estudada por alguns pesquisadores (Goetz \& Vieira, 2009; Muzio, 1998; Seabra, 2007) que compartilham a classificação de Muzio (1998): paternidade tradicional (representada por características como dar permissões, prover alimentos, impor castigos, pôr "pulso firme" através de críticas e recomendações à mãe); paternidade com manifestações de mudança (inclui as características do pai tradicional, acrescentando, ocasionalmente, outras tarefas como, por exemplo, de cuidado, envolvimento nas tarefas escolares, levar ou buscar o filho na escola ou médico); paternidade não tradicional (o pai compartilha igualmente as funções com a mãe).

O período de transição entre os papéis exercidos na família ocidental contemporânea é marcado, justamente, pela presença dos três estilos de paternidade. Dependendo do tipo de arranjo familiar, a participação paterna nos cuidados com os filhos e seu envolvimento em atividades domésticas são vistos como "ajuda". Ou seja, essas são atividades ainda não "pertencem" aos homens. A divisão igualitária dessas atividades está relacionada também a uma necessidade de mudança na própria mentalidade feminina, estando as mães dispostas a aprender novos papéis e a compartilhar antigas funções com os pais de seus filhos. Durante os dois primeiros anos de vida, quando os cuidados físicos são muitos, a paternidade ainda é vista socialmente como secundária, embora vários estudos tenham mostrado a possibilidade do bebê fazer vínculos seguros com mais de um cuidador. Esse período de transição dos papéis familiares parece levar a uma sobreposição de características de maternidade e paternidade tradicionais, conduzindo ao surgimento de diferentes tipos de paternidade. Como aponta Muzio (1998, p. 169) "se a mãe já não é a única a dispensar amor, tampouco o pai é, então, a encarnação exclusiva de autoridade, da lei e do mundo exterior".
Os estudos discutidos apresentam um panorama diverso, indicações variadas de participação paterna, de acordo com a idade do filho, e algumas tendências de mudança na paternidade tradicional. No entanto, não foram identificados estudos longitudinais na população brasileira que buscassem ampliar a compreensão do problema. Portanto, o objetivo geral deste trabalho foi investigar a organização da paternidade em famílias urbanas contemporâneas na cidade do Rio de Janeiro, tendo como foco principal a participação paterna nos "cuidados" com a criança em três momentos de seu desenvolvimento (5, 20 e 36 meses). Especificamente investigaram-se em que aspectos a participação paterna é mais ou menos frequente; a existência ou não de uma relação entre a participação paterna e a faixa etária da criança; como as mães percebem e incentivam esta participação e se o comportamento paterno real se aproxima ou se desvia do comportamento paterno ideal considerado pela mãe.

\section{MÉTODO}

\section{Participantes}

Foram acompanhadas sete famílias, que já haviam participado de outro estudo com o grupo de pesquisa Interação Social e Desenvolvimento ${ }^{1}$, residentes na cidade do Rio de Janeiro em três momentos distintos da vida de seus filhos primogênitos $(5,20$ e 36 meses). As famílias eram de nível socioeconômico médio e os pais moravam junto com seus filhos. A idade dos pais, na época das entrevistas, variou de 27 a 38 anos, tendo como idade média 33 anos. A escolaridade de cinco pais era o nível superior e de dois pais, o ensino médio (pai 2 e pai 5). Quatro dos pais (pai 1, pai 2, pai 4 e pai 6) tinham outros filhos mais novos com a mãe do filho participante da pesquisa e apenas um pai (pai 5) tinha outros filhos mais velhos de uma união anterior. O número de horas diárias longe do filho variou de cinco a doze horas, tendo como média nove horas. Todos os pais residiam junto com a mãe de seus filhos. A idade das mães variou de 25 a 42 anos, tendo como média, 33 anos. Apenas uma das mães (mãe 5) tinha como escolaridade o ensino médio, as demais tinham o nível superior. Todas as mães trabalhavam fora e ficavam longe dos filhos de cinco a doze horas diárias, tendo como média sete horas. 
Tabela 1

Dados Familiares

\begin{tabular}{|c|c|c|c|c|c|c|c|}
\hline \multicolumn{2}{|c|}{ No. de filhos } & Idade Paterna & $\begin{array}{c}\text { Idade } \\
\text { Materna }\end{array}$ & $\begin{array}{l}\text { Profissão } \\
\text { Paterna }\end{array}$ & $\begin{array}{l}\text { Profissão } \\
\text { Materna }\end{array}$ & $\begin{array}{l}\text { Horas longe } \\
\text { (pai) }\end{array}$ & $\begin{array}{l}\text { Horas longe } \\
\text { (mãe) }\end{array}$ \\
\hline \multicolumn{2}{|l|}{2} & 36 & 42 & Professor & Professora & $6 \mathrm{~h}$ & $6 \mathrm{~h}$ \\
\hline \multicolumn{2}{|l|}{2} & 27 & 25 & Comerciante & Economista & $11 \mathrm{~h}$ & $6 \mathrm{~h}$ \\
\hline \multicolumn{2}{|c|}{1} & 34 & 41 & Biólogo & Professora & $8 \mathrm{~h}$ & $8 \mathrm{~h}$ \\
\hline \multicolumn{2}{|c|}{2} & 35 & 34 & Eng. químico & Eng. química & $12 \mathrm{~h}$ & $12 \mathrm{~h}$ \\
\hline 1 (mat.) & & 38 & 30 & Motorista & Professora & $9 \mathrm{~h}$ & $4 \mathrm{~h}$ \\
\hline \multicolumn{2}{|l|}{3} & 29 & 29 & Policial & Contadora & $12 \mathrm{~h}$ & $10 \mathrm{~h}$ \\
\hline \multicolumn{2}{|l|}{1} & 33 & 30 & Metereologista & Publicitária & $5 \mathrm{~h}$ & $5 h$ \\
\hline Média & 1,71 & 33 & 33 & & & $9 \mathrm{~h}$ & $7 \mathrm{~h}$ \\
\hline $\begin{array}{l}\text { Desv. } \\
\text { Padrão }\end{array}$ & 0,75 & 3,89 & 6,38 & & & 2,82 & 2,87 \\
\hline
\end{tabular}

\section{INSTRUMENTOS}

1) Estilo Paterno: Este instrumento foi desenvolvido por M. H. Bornstein e colaboradores no National Institute for Child Health and Human Development. Foi traduzido e adaptado no Brasil por Rodolfo de Castro Ribas Jr. ${ }^{2}$ e Neide Al-Cici ${ }^{3}$, e utilizado no projeto de pesquisa Interação Mãe-Bebê e o Desenvolvimento Infantil: Um Estudo Longitudinal e Transcultu- $\mathrm{ral}^{4}$. É constituído de 17 itens, que fornecem como resultado a satisfação da mãe com o envolvimento e comportamento do pai em relação ao(s) filho(s) e do que considera ideal e, indiretamente, avalia a satisfação da mãe com o suporte fornecido pelo pai. Este instrumento fornece uma escala de um a cinco e foi aplicado às mães quando os filhos estavam com cinco, vinte e trinta e seis meses. Exemplo:
1

Quase nunca
2

Ocasionalmente
3
4

- _ O pai da minha criança passa um tempo brincando com nossa criança.

- _ O ideal é que o pai da minha criança passe um tempo brincando com nossa criança.

Os itens deste instrumento estão subdivididos em quatro domínios: Cuidados básicos (relacionados à promoção do bem-estar e saúde da criança, promovendo sustento, cuidados de rotina, proteção, supervisão, higiene, conforto, etc. Estes cuidados atendem às necessidades biológicas, físicas e de saúde da criança); Domínio social (inclui os comportamentos visuais, verbais, afetivos e físicos utilizados para engajar as crianças emocionalmente e promover trocas interpessoais); Domínio didático (envolve o conjunto de estratégias utilizadas pelos pais para estimularem suas crianças a se engajarem e compreenderem o ambiente e entrarem no mundo da aprendizagem); Domínio material (inclui as formas pelas quais os pais oferecem, organizam e estruturam o ambiente no qual a criança vive). Os resultados foram analisados em escores gerais e por domínios.

2) Entrevista semiestruturada: Foi realizada uma entrevista com o pai na última etapa da coleta de dados (36 meses) com a finalidade de obter informações a respeito dos cuidados paternos com os filhos nas diferentes idades, quais os fatores que o motivaram nesta participação, o grau de importância dado as diferentes formas de participação, a divisão dos trabalhos domésticos e cuidados com os filhos, entre outros.

3) Descrição familiar: Este instrumento teve por finalidade obter informações sobre as condições socioeconômicas da família (escolaridade, profissão, número 
de filhos, etc.), além do número de horas diárias em que pai e mãe permanecem longe do filho.

4) Consentimento livre e esclarecido: Forneceu informações a respeito da natureza da pesquisa, do envolvimento da família, dos possíveis riscos e desconfortos, da confidencialidade, e do não recebimento de benefícios e pagamentos.

\section{PROCEDIMENTOS}

Foi realizada uma aplicação do instrumento Estilo Paterno às mães, em diferentes momentos do desenvolvimento infantil (5, 20 e 36 meses). A aplicação do instrumento nas duas primeiras etapas foi realizada em um estudo anterior pelo grupo de pesquisa Interação Social e Desenvolvimento. A entrevista semiestruturada foi realizada com os pais durante a visita de aplicação do instrumento Estilo Paterno, quando o filho estava com trinta e seis meses, na residência da família e sem a presença de nenhum outro membro familiar no ambiente. Foi feito o uso do gravador para o registro das entrevistas e posterior transcrição. As entrevistas duraram entre quinze e quarenta minutos, com duração média de 25 minutos.

\section{ANÁLISE DOS DADOS}

As entrevistas foram transcritas na íntegra e preparadas para análise. A análise seguiu procedimentos de análise de conteúdo temática (Bardin, 2002). Foi realizada uma leitura flutuante, depois o desmembramento do texto em unidades, buscando identificar núcleos de sentido ou temas. Os temas identificados foram: ser pai, mudança de vida, conhecimento para educar e cuidar, expectativas para o filho quando adulto, divisão de tarefas nos cuidados com o filho, participação em diferentes idades, estilo paterno, tarefas que mais gostam ou menos gostam de realizar com os filhos, participação na escola e avô paterno. Os escores do Estilo Paterno foram calculados e os dados foram analisados quantitativamente comparando as médias e desvios, realizando uma comparação entre a percepção materna do pai real e ideal nas diferentes idades. Foi realizada uma articulação dos resultados encontrados no instrumento Estilo Paterno com os resultados das entrevistas.

\section{RESULTADOS E DISCUSSÃO}

Primeiramente serão apresentados os dados das entrevistas com os pais e, posteriormente, os dados comparativos do instrumento Estilo Paterno. Por fim, será realizada uma análise geral do estudo. A entrevista realizada com os pais teve por objetivos: coletar informações sobre sua compreensão acerca da paternidade; as mudanças ocorridas após a paternidade; os conhecimentos necessários para cuidar e educar os filhos; a participação paterna nos cuidados com os filhos desde o nascimento até o momento da entrevista; a divisão dos cuidados e dos trabalhos domésticos entre o pai e mãe; algumas satisfações e insatisfações em relação aos cuidados com o filho.

O primeiro tema identificado foi o "ser pai". As respostas não são precisas, os pais não definem bem o que é ser pai para eles, mas relataram aspectos que envolvem a paternidade, dentre eles: a importância de sua participação e os aspectos afetivo, pedagógico, espiritual e moral-ético. Esse tema esteve presente nas repostas de cinco pais. São exemplos dessas falas: "acho que é você estar ali presente, acompanhando passo a passo o teu filho" - (pai 3); "ser pai é uma coisa muito gratificante, porque você aprende muito com o filho. Você recebe muito" - (pai 1); "Eu acho que você aprende muito ao mesmo tempo que você tenta ensinar, ...acho que ser pai pra mim é ensinar e aprender" - (pai 3); "um grande presente de Deus" (pai 7); “...uma redescoberta do mundo. São outros valores, , ...eu mudei a maneira de pensar em relação a muita coisa" - (pai 4).

Todos os pais relatam mudanças em suas vidas com a paternidade. Três identificaram mudanças em prioridades e estilo de vida: "nossas prioridades mudaram" (pai 3); "você radicalmente muda o seu estilo de vida em função dele." (pai 7). Seis dos participantes revelam o aumento de preocupação com o mundo e com a vida: "a gente continua fazendo besteiras, mas pensa um pouco mais antes de fazê-las" (pai 1); "você passa a ficar preocupado com tudo. Eu fiquei muito mais medroso" (pai 2); "me fez me importar mais com o mundo" (pai 3). Finalmente, dois pais identificaram também mudanças referentes à conjugalidade e a sua relação com a paternidade, "tudo que a gente fazia era em benefício de nós dois mesmo e agora não (pai 3), "ele nos une" (pai 5). Pode-se sintetizar as respostas sobre esse tema dizendo que os pais percebem mudanças em sua vida referentes ao exercício da paternidade, envolvendo preocupações, responsabilidade, ampliação dos núcleos familiares, além do conjugal.

Em relação ao tema conhecimentos necessários para cuidar e educar, cinco pais o incluem em suas respostas. Para eles é essencial "entender sobre comportamento, carências, necessidades" (pai 3), e tam- 
bém que "saber períodos do desenvolvimento infantil são importantes para não antecipá-los" (pai 1). Entre conhecimentos de desenvolvimento, o aspecto emocional é incluído, assim como princípios morais. São exemplos de falas referentes a esse último aspecto: "eu acho que a gente precisa ter princípios para ter facilidade até na hora de orientar" (pai 4), "é fantástico você ver que o caráter de uma pessoa tá dependendo exclusivamente da tua forma de lidar com a criança" (pai 7). Incluem também como importantes os seguintes fatos: "estar sempre presente, conversar e ter uma capacidade financeira suficiente para o mínimo possível" (pai 1).

Ainda sobre esse tema, na busca dos conhecimentos que consideram importantes, quatro dos sete pais relataram que utilizam livros e revistas: "a gente estuda livros sobre o desenvolvimento infantil" (pai 1), "a gente lê bastante revistas mesmo" (pai 3), "Delamare tem algumas dicas" (pai 4). Os pais entrevistados parecem buscar conhecimento principalmente em revistas de grande circulação e talvez não estejam encontrando nelas as repostas que buscam. Como indica Santos (2004), essas revistas para pais são ainda muito voltadas para mães, com uma imagem paterna muitas vezes limitada a determinadas tarefas de entretenimento com os filhos, ou apenas mostrando o lado afetivo. Apresentam muito pouco o pai como participante ativo nos cuidados com os filhos.

Além de revistas, quatro pais mencionaram que buscam ajuda de diversos profissionais para obterem conhecimentos, "a gente pede informações a pessoas amigas que são capacitadas, a um médico, a um psicólogo, fonoaudiólogo..." (pai 1), "Orientação, inclusive na escola" (pai 4), "tá buscando informações, experiências com outros pais, até pra você formar uma ideia sobre determinada coisa" (pai 7).

Finalmente, cinco pais buscam seus próprios recursos pessoais e consideram seu exemplo a melhor maneira para ajudar na formação do filho: "eu preciso procurar fazer as coisas certas, é dentro de casa que você vai mostrando tudo" (pai 2), "acho que exemplo funciona mais, mostrar o que é ser realizado, o que é ser equilibrado, o que é ter justiça, e que é possivel discutir as coisas" (pai 3), "o pai é o espelho, então eu não fumo, não bebo, e é trabalho-casa, casa-trabalho" (pai 5), "E que ele tenha segurança na relação pai e filho e mostrar que eu sou coerente sempre nas minhas atitudes" (pai 7). Estes resultados estão de acordo com os de Bandeira (2009), em que os pais têm uma preocupação grande com o investimento emocional. Pode-se sintetizar as repostas com esse tema, indicando que os pais consideram importantes informações diversas sobre o cuidado de seus filhos, não se limitando a padrões de desenvolvimento motor ou cognitivo. Aspectos emocionais e morais são valorizados em algumas respostas. Para obter essas informações ou elementos que consideram importantes, recorrem a material impresso (livros e revistas, a especialistas e a seus próprios recursos pessoais).

No que concerne à divisão de tarefas nos cuidados com o filho, todos os pais relataram dividir as tarefas com as mães, "às vezes eu faço até mais que ela. Teve uma fase que realmente andei ausente neste aspecto, mas hoje eu participo muito" (pai 2), "A gente divide assim como dá, na verdade não tem um esquema" (pai 3), "a gente divide tudo. A única coisa que eu não fiz foi amamentar. Eu não abro mão de nada. Existem tarefas que eu exercito com menos frequência, mas por força de necessidade de estar ausente" (pai 4). Afirmam que "dever de casa, essas coisas, ele faz melhor comigo, eu tenho mais paciência" (pai 6), "não existe um papel pra diferir. Dentro do casal existia aquela figura do pai passivo, do pai que era responsável pelo provento da família. Mudou muito, né? E hoje, fica muito claro que os dois têm papel importante" (pai 7).

A fala desses pais parece corroborar os resultados de Bandeira (2009) e Silva e Piccinini (2007) que indicam que os pais estão mais atentos aos cuidados básicos. Trindade e cols. (1997), também em uma amostra com pais brasileiros, argumentam que quanto mais alto o nível de escolaridade do pai, mais ele tende a compartilhar os cuidados com os filhos. A maioria dos pais entrevistados tem um alto nível de escolaridade.

Um dos pais relatou acreditar que ainda existem tarefas direcionadas à mulher: "as questões que são socialmente delegadas à mulher, as que requerem uma habilidade feminina, como cortar unha, eu não consigo fazer. Cada um tem seu papel dentro da sociedade e a gente até troca esses papéis quando é possível" (pai 1). Essa fala é na mesma direção dos estudos de Souza e cols. (2007) e Bustamante e Bonfim (2005) que afirmam que alguns homens ainda consideram que os cuidados corporais com a criança são atribuições femininas.

Como mencionado na literatura (Fleck \& Wagner, 2003; Rocha-Coutinho, 2003), alguns ainda vêem seu papel como de ajuda. A palavra "ajuda" ainda apareceu no discurso de quatro pais: "eu procuro ajudar quando eu tô em casa" (pai 1), "fica muito sobrecarregado em cima dela, eu procuro ajudar" (pai 6). 
Dos sete pais, três não relataram tarefas que não realizam com o filho "...tem as que ela mais faz" (pai 3 ), e quatro pais, se puderem, delegam os cuidados para a mãe em algumas tarefas: "quando a mãe tá eu deixo mais a mãe"(pai 3), "dar banho não é das minhas preferidas, mas se ela tiver ocupada, eu vou fazer" (pai 7). Seabra e cols. (2001) discutem também que as mães percebem as atividades relacionadas ao conforto físico como atribuição delas. Os pais estariam mais engajados na socialização e estabelecimento de regras, porém, apesar de haver essa tendência, os pais estão se engajando cada vez mais em todas as tarefas.

Em geral os pais percebem sua participação como variando de acordo com a idade de seus filhos o que é consistente com os dados de Silva e Piccinini (2007). Apenas dois pais não consideram haver diferença em sua participação ao longo das diferentes idades. A faixa etária da criança é vista como significativa: "recém-nascido fica muito mais difícil, diferença é mais assim recém-nascido pra agora. Tem uma grande diferença porque enquanto tá mamando você não consegue ficar com ela sozinho" (pai 2). Também na mesma direção das observações de Diniz (1999) e Silva e Piccinini (2007), três pais falam da diferença na participação por contingência do horário de trabalho "quando era menorzinha eu cuidava mais da higiene, mas por força do nosso horário" (pai 3).

A maioria dos pais (cinco pais) está satisfeita com seu estilo de cuidados paternos: "eu gosto do jeito que eu sou pai porque eu acho que funciona. No fundo, não sei nem se é vaidade, mas eu gosto do jeito que eu sou pai" (pai 3), "eu me considero um bom pai na minha maneira de ser. Até pelo exemplo que dou pra ele" (pai 5), "eu tô satisfeito em relação a minha melhora das dificuldades que eu tive no início" (pai 7). Apesar dessa satisfação, seis pais afirmaram alguns pontos em que gostariam de mudar "Gostaria de estar mais presente na escola, mas às vezes, não é compatível" (pai 1), "eu poderia ser mais paciente, tolerante" (pai 2), "às vezes, eu tenho preguiça, eu não sou solícito" (pai 3), "eu superprotegia, mas isso eu fui trabalhando, e acho que hoje eu tô melhor" (pai 4). Também comentaram que gostariam de mudar suas condições de vida e trabalho para se dedicarem mais ao filho, "eu não queria mudar no sentido de pai, mas a parte financeira, ter uma condição melhor pra oferecer muitas coisas aos meus filhos" (pai 5), "eu gostaria de ter um pouco mais de tempo" (pai 6).

Assim como se consideram bons pais, de uma forma geral, os pais entrevistados consideram que as mães de seus filhos estão satisfeitas com seus estilos paternos. Dois deles, entretanto identificam pontos em que julgam que a mãe gostaria que houvesse mudança "ela me acha um bom pai, mas acha que eu tinha também que ser mais solícito" (pai 3), "não deve estar satisfeita por eu não estar muito presente” (pai 6). Talvez isso seja indicação do que Seabra e cols. (2001) observaram no sentido de que o nível de satisfação das mães, em relação aos estilos paternos de seus cônjuges, ainda ser ambivalente.

A tarefa que três pais consideram mais prazerosa de ser realizada é brincar "eu gosto de brincar com meu filho" (pai 1), "mesmo que eu esteja cansado, eu busco uma energia a mais pra estar brincando, sentar no chão..." (pai 7). São respostas consistentes com as observações de Jablonski (1999) sobre o que os pais mais fazem com seus filhos. Na mesma direção do lúdico e do prazer, outra atividade que mais dá prazer a dois dos pais é passear: "de levar nos lugares que eu gosto. Ensinar a gostar do que eu gosto" (pais 3), "gosto de ir a teatrinho, de andar na rua, tipo exibir mesmo" (pai 1).

Em relação às atividades que menos gostam de fazer os pais disseram que "depende da situação. Tem dia que tá com calor e gosta de tomar banho, tem dia que tá frio e eu não gosto de tomar banho com ele, é melhor dar banho nele." (pai 1). As atividades de cuidado foram relatadas por dois pais como as menos preferidas, "o que eu menos gosto de fazer é trocar fralda" (pai 1), "o que eu menos gosto é dar banho"(pai 3). Apenas um pai relatou gostar de realizar uma atividade de cuidado: "gosto de tomar banho com ele" (pai 1). Talvez esses resultados estejam relacionados ainda aos aspectos da paternidade tradicional, em que os cuidados físicos ficam sob a responsabilidade da mãe (Bittman, 1995; Gunter \& Gunter, 1990).

Em contrapartida, ao contrário do que seria esperado em um modelo de paternidade tradicional (Muzio, 1998), a maioria dos pais (seis pais) disse não gostar dos momentos em que são necessários aplicar algum limite ou impor regras para a criança, "eu não gosto muito de brigar com ela, mas eu brigo, é uma questão de educar mesmo, mas eu não gosto não" (pai 3), "o que eu não gosto é quando eu tenho que repreender" (pai 4), "ninguém gosta de chamar a atenção, de castigar um filho" (pai 7). Na paternidade tradicional o pai é a figura que exerce o "poder", determinando as regras familiares e estabelecendo condutas para que as mesmas sejam cumpridas. Os pais entrevistados parecem se distanciar, neste aspecto, do "pai tradicional". Em geral, o resultado das entrevistas indica que os pais participantes ainda oscilam entre a paternidade 
tradicional e a paternidade não tradicional, predominando a "paternidade com manifestações de mudança" (Muzio, 1998).

Em relação ao instrumento Estilo Paterno, as mães atribuem uma média de participação do pai real $(3,64)$ e ideal $(4,33)$ menor aos cinco meses, tendo um ligeiro aumento aos vinte meses $(3,99$ e 4,38 respectivamente), tornando a diminuir aos trinta e seis meses (3,76 e 4,09 respectivamente), como observamos na
Tabela 1. Os valores máximo e mínimo nesse instrumento são, respectivamente, zero e cinco. É interessante notar que aos trinta e seis meses a expectativa das mães em relação à participação paterna (Pai ideal) apresenta a menor média $(4,09)$ comparando com as demais idades. Esses resultados indicam que, em geral, as mães esperam mais (ideal) do que os pais fazem, mas que essa expectativa diminui com a idade.

Tabela 2

Comparação da Percepção Materna Sobre a Participação do Pai Real e Ideal aos 5, 20 e 36 Meses

\begin{tabular}{ccccccc}
\hline \multirow{2}{*}{ Idade } & \multicolumn{2}{c}{ Cinco meses } & \multicolumn{2}{c}{ 20 meses } & \multicolumn{2}{c}{$\mathbf{3 6}$ meses } \\
\cline { 2 - 7 } & Real & Ideal & Real & Ideal & Real & Ideal \\
\hline Média & 3,64 & 4,33 & 3,99 & 4,38 & 3,76 & 4,09 \\
Desvio Padrão & 0,73 & 0,35 & 0,50 & 0,24 & 0,62 & 0,41 \\
\hline
\end{tabular}

Fazendo uma análise dos domínios separadamente, observamos que no domínio social as mães atribuem maior participação dos pais aos vinte meses (média $4,31)$ e a maior expectativa de engajamento ocorre aos cinco meses (média 4,66), decrescendo gradativamente conforme a idade da criança. $\mathrm{O}$ ato de o pai brincar com a criança manteve a mesma média $(3,86)$ em todas as faixas etárias e a expectativa da mãe em relação ao brincar apresenta-se maior aos cinco meses (média 4,57), diminuindo gradativamente ao longo da idade do filho (médias 4,43 e 4,00 respectivamente). As mães afirmam que os pais respondem de forma rápida e positiva quando a criança quer atenção mais eficientemente aos cinco e vinte meses (médias 4,14).
A média de expectativa das mães em relação a esse aspecto também é menor aos trinta e seis meses (média 3,57). As mães demonstram grande satisfação com a forma de o pai oferecer mostras positivas de afeto, carinho e atenção para a criança em todas as idades, apresentando médias idênticas para o pai real e para pai ideal com cinco e trinta e seis meses (médias $4,86)$. Aos vinte meses a média do pai real é a máxima $(5,0)$ e a do pai ideal um pouco menor $(4,86)$. O fato de o pai estar atento ao que a criança está sentindo, gera menor satisfação nas mães com filhos de 36 meses (média 4,00) e a maior expectativa de engajamento ocorre aos cinco meses (média 4,71).

Tabela 3

Comparação da Percepção Materna Sobre a Participação do Pai Real e Ideal no Domínio Social

\begin{tabular}{|c|c|c|c|c|c|c|c|c|}
\hline & $\begin{array}{l}\text { Mãe } \\
5 \mathrm{~m}\end{array}$ & $\begin{array}{l}\text { Mãe } \\
5 \mathrm{~m}\end{array}$ & $\begin{array}{l}\text { Mãe } \\
20 \mathrm{~m}\end{array}$ & $\begin{array}{l}\text { Mãe } \\
20 \mathrm{~m}\end{array}$ & $\begin{array}{c}\text { Mãe } \\
36 \mathrm{~m}\end{array}$ & $\begin{array}{c}\text { Mãe } \\
36 \mathrm{~m}\end{array}$ & $\begin{array}{c}\text { Pai } \\
36 \mathrm{~m}\end{array}$ & $\begin{array}{c}\text { Pai } \\
36 \mathrm{~m}\end{array}$ \\
\hline Questão & Real & Ideal & Real & Ideal & Real & Ideal & Real & Ideal \\
\hline Brincar & 3,86 & 4,57 & 3,86 & 4,43 & 3,86 & 4,00 & 3,57 & 4,29 \\
\hline Conversar & 3,86 & 4,57 & 4,43 & 4,29 & 4,43 & 4,29 & 3,57 & 4,29 \\
\hline Atenção & 4,14 & 4,57 & 4,14 & 4,43 & 3,71 & 3,57 & 4,00 & 4,00 \\
\hline Afeto & 4,86 & 4,86 & 5,00 & 4,86 & 4,71 & 4,71 & 4,86 & 4,86 \\
\hline $\begin{array}{l}\text { Atenção ao que } \\
\text { está sentindo }\end{array}$ & 4,14 & 4,71 & 4,14 & 4,43 & 4,00 & 4,43 & 4,57 & 4,57 \\
\hline Média & 4,17 & 4,66 & 4,31 & 4,49 & 4,14 & 4,20 & 4,11 & 4,40 \\
\hline Desvio Padrão & 0,37 & 0,11 & 0,39 & 0,19 & 0,37 & 0,39 & 0,52 & 0,29 \\
\hline
\end{tabular}


No domínio de cuidado básico observamos que o engajamento aumenta gradativamente conforme a idade da criança (médias 3,$21 ; 3,50 ; 3,71$, respectivamente) e que aos 36 meses as mães apresentam menor expectativa de participação paterna (média 3,93). A resposta rápida e apropriada pelo pai ao desconforto da criança, segundo as mães, vai aumentando juntamente com a idade da criança (médias 3,$57 ; 3,86$ e
4,14 respectivamente) e a expectativa das mães em relação ao engajamento paterno é maior aos cinco meses (média 4,29). O atendimento com eficiência, por parte dos pais, às necessidades do dia-a-dia da criança também aumenta com o crescimento do filho (média 3,29 aos trinta e seis meses) e a menor expectativa de participação ocorre aos trinta e seis meses (média 3,86).

Tabela 4

Comparação da Percepção Materna Sobre a Participação do Pai Real e Ideal no Domínio de Cuidado

\begin{tabular}{lcccccccc}
\hline & Mãe & Mãe & Mãe & Mãe & Mãe & Mãe & Pai & Pai \\
& $\mathbf{5 m}$ & $\mathbf{5 m}$ & $\mathbf{2 0 m}$ & $\mathbf{2 0 ~} \mathbf{m}$ & $\mathbf{3 6 ~ \mathbf { m }}$ & $\mathbf{3 6 ~ \mathbf { m }}$ & $\mathbf{3 6 ~ \mathbf { m }}$ & $\mathbf{3 6} \mathbf{~ m}$ \\
\hline Questão & Real & Ideal & Real & Ideal & Real & Ideal & Real & Ideal \\
\hline Mal-estar & 3,57 & 4,29 & 3,86 & 4,14 & 4,14 & 4,00 & 4,29 & 4,43 \\
Necessidades diárias & 2,86 & 4,14 & 3,14 & 4,43 & 3,29 & 3,86 & 3,57 & 4,14 \\
\hline Média geral & $\mathbf{3 , 2 1}$ & $\mathbf{4 , 2 1}$ & $\mathbf{3 , 5 0}$ & $\mathbf{4 , 2 9}$ & $\mathbf{3 , 7 1}$ & $\mathbf{3 , 9 3}$ & $\mathbf{3 , 9 3}$ & $\mathbf{4 , 2 9}$ \\
Desvio Padrão & $\mathbf{0 , 3 6}$ & $\mathbf{0 , 0 7}$ & $\mathbf{0 , 3 6}$ & $\mathbf{0 , 1 4}$ & $\mathbf{0 , 4 3}$ & $\mathbf{0 , 0 7}$ & $\mathbf{0 , 3 6}$ & $\mathbf{0 , 1 4}$ \\
\hline
\end{tabular}

Em relação ao domínio material, para as mães, tanto a participação paterna (média 3,75 ) quanto à expectativa das mães (média 4,43) são maiores aos vinte meses. O oferecimento de atividades com outras crianças da mesma idade é maior aos trinta e seis meses (média 3,43) e a expectativa das mães de maior engajamento paterno ocorre aos vinte meses (média 4,43). A organização e estruturação do ambiente pelo pai apresentam médias iguais $(4,71)$ para o pai real e ideal aos vinte meses, sendo a média real um pouco menor que nas demais idades. A média do pai ideal $(4,71)$ se manteve a mesma em todas as idades. $\mathrm{O}$ oferecimento de práticas esportivas pelo pai da criança é maior aos vinte meses (média 4,71). Também nesta idade as mães apresentam a maior média $(4,71)$ de expectativa de participação. $\mathrm{O}$ oferecimento de brinquedos e objetos pelo pai para a criança brincar e explorar, assim como a expectativa materna em relação a este fato diminui com o desenvolvimento da criança. Aos cinco meses a média $(4,57)$ de expectativa materna em relação à participação do pai se iguala à média do pai real.

Tabela 5

Comparação da Percepção Materna Sobre a Participação do Pai Real e Ideal no Domínio Material

\begin{tabular}{lcccccccc}
\hline & Mãe & Mãe & Mãe & Mãe & Mãe & Mãe & Pai & Pai \\
& $\mathbf{5 m}$ & $\mathbf{5 m}$ & $\mathbf{2 0 m}$ & $\mathbf{2 0 ~} \mathbf{~}$ & $\mathbf{3 6 ~ \mathbf { m }}$ & $\mathbf{3 6} \mathbf{~ m}$ & $\mathbf{3 6 ~ \mathbf { m }}$ & $\mathbf{3 6} \mathbf{~ m}$ \\
\hline Questão & Real & Ideal & Real & Ideal & Real & Ideal & Real & Ideal \\
\hline Atividades sociais & 2,86 & 4,14 & 3,29 & 4,43 & 3,43 & 3,71 & 3,43 & 4,29 \\
Ambiente & 4,86 & 4,71 & 4,71 & 4,71 & 4,86 & 4,71 & 4,43 & 4,57 \\
Práticas esportivas & 2,43 & 3,86 & 3,00 & 4,29 & 2,71 & 3,86 & 3,29 & 3,86 \\
Oferecimento de objetos & 4,57 & 4,57 & 4,00 & 4,29 & 3,57 & 4,29 & 4,00 & 4,29 \\
\hline Média geral & $\mathbf{3 , 6 8}$ & $\mathbf{4 , 3 2}$ & $\mathbf{3 , 7 5}$ & $\mathbf{4 , 4 3}$ & $\mathbf{3 , 6 4}$ & $\mathbf{4 , 1 4}$ & $\mathbf{3 , 7 9}$ & $\mathbf{4 , 2 5}$ \\
Desvio Padrão & $\mathbf{1 , 0 5}$ & $\mathbf{0 , 3 4}$ & $\mathbf{0 , 6 7}$ & $\mathbf{0 , 1 7}$ & $\mathbf{0 , 7 7}$ & $\mathbf{0 , 3 9}$ & $\mathbf{0 , 4 6}$ & $\mathbf{0 , 2 6}$ \\
\hline
\end{tabular}

No domínio didático observamos que as maiores médias do pai real $(4,07)$ e ideal $(4,33)$ ocorrem aos vinte meses. $\mathrm{O}$ fato de o pai dar tempo para a criança ficar sozinha e aprender por si também é maior aos vinte meses (média 4,14), o mesmo ocorre com a expectativa das mães (média 4,43). Em relação ao pai chamar a atenção da criança para seguir regras e ser bem comportada, segundo as mães, há maior engajamento aos trinta e seis meses (média 4,71). O mesmo 
resultado ocorre na expectativa das mães (média 4,29). O uso da disciplina e firmeza pelo pai, necessário para ensinar o respeito pela autoridade, aumenta junto com a idade da criança (médias 3,29; 3,86 e 4,71 respectivamente). A expectativa das mães em relação a este fato é menor aos cinco meses (média 3,57) que nas demais idades. $\mathrm{O}$ auxílio à criança para aprender a falar melhor, segundo as mães, é maior aos vinte meses (média 4,00). É nesta faixa etária que as mães têm a menor expectativa de engajamento paterno (média 4,29 ), sendo nesta idade quando as médias do pai ide- al e real mais se aproximam. As mães atribuem aos pais menos paciência quando a criança se comporta mal quanto mais velha a criança (média 3,86 ) e a maior expectativa materna em relação a este fato ocorre aos vinte meses (média 4,86). As mães com filhos de vinte meses e trinta e seis meses parecem estar satisfeitas com a flexibilidade do pai sobre o comportamento que ele espera da criança. Em ambas as idades a médias real e ideal foram idênticas (4,43 aos vinte meses e 3,57 aos trinta e seis meses), mas estas são maiores aos vinte meses.

Tabela 6

Comparação da Percepção Materna Sobre a Participação do Pai Real e Ideal no Domínio Didático

\begin{tabular}{lcccccccc}
\hline & Mãe & Mãe & Mãe & Mãe & Mãe & Mãe & Pai & Pai \\
& $\mathbf{5 m}$ & $\mathbf{5 m}$ & $\mathbf{2 0 m}$ & $\mathbf{2 0 m}$ & $\mathbf{3 6 m}$ & $\mathbf{3 6 m}$ & $\mathbf{3 6 m}$ & R6 $\mathbf{m}$ \\
\hline Questão & Real & Ideal & Real & Ideal & Real & Ideal & Real & Ideal \\
\hline Aprender sozinha & 3,29 & 4,00 & 4,14 & 4,43 & 4,00 & 3,71 & 4,14 & 4,00 \\
Regras & 3,57 & 4,00 & 3,86 & 4,00 & 4,71 & 4,29 & 4,71 & 4,86 \\
Respeito pela autoridade & 3,29 & 3,57 & 3,86 & 4,00 & 4,00 & 4,00 & 4,71 & 4,43 \\
Aprender a falar & 2,57 & 4,57 & 4,00 & 4,29 & 3,43 & 4,57 & 3,86 & 4,57 \\
Mau comportamento & 4,29 & 4,57 & 4,14 & 4,86 & 3,86 & 4,14 & 3,86 & 4,00 \\
Flexibilidade & 4,00 & 4,14 & 4,43 & 4,43 & 3,57 & 3,57 & 4,14 & 4,14 \\
\hline Média geral & $\mathbf{3 , 5 0}$ & $\mathbf{4 , 1 4}$ & $\mathbf{4 , 0 7}$ & $\mathbf{4 , 3 3}$ & $\mathbf{3 , 9 3}$ & $\mathbf{4 , 0 5}$ & $\mathbf{4 , 2 4}$ & $\mathbf{4 , 3 3}$ \\
Desvio Padrão & $\mathbf{0 , 5 5}$ & $\mathbf{0 , 3 5}$ & $\mathbf{0 , 2 0}$ & $\mathbf{0 , 2 9}$ & $\mathbf{0 , 4 1}$ & $\mathbf{0 , 3 4}$ & $\mathbf{0 , 3 6}$ & $\mathbf{0 , 3 2}$ \\
\hline
\end{tabular}

Fazendo uma articulação das entrevistas com os resultados obtidos no Estilo Paterno observamos que, de uma forma geral os pais consideram que as mães estão satisfeitas com seu estilo paterno, mas as mães demonstram que gostariam de um maior envolvimento do pai com os filhos. A maioria dos pais e mães envolvidos neste estudo percebe diferença na participação paterna ao longo do desenvolvimento, quanto menor a idade, menor a participação paterna. Piccinini e cols. (2004) discutem que o envolvimento paterno nos primeiros meses de vida do bebê tende a ser menor nas famílias em que as mulheres resistem a essa participação, excluindo os pais dos cuidados básicos com o bebê.

As atividades que mais dão prazer aos pais em relação aos filhos são as atividades lúdicas, como afirma Jablonski (1999); os pais costumam interagir mais com os filhos nos momentos de jogos e humor. Bittman (1995) e Gunter e Gunter (1990) afirmam que a participação dos pais ocorre nas horas de lazer enquanto as mães se encarregam das tarefas rotineiras e cotidianas. As mães, porém, em todas as faixas etárias consideram que o envolvimento paterno poderia ainda ser maior neste quesito. Os momentos de imposição de limites e regras são considerados pelos pais os menos prazerosos e as mães consideram que os pais estão mais envolvidos nestas tarefas com os filhos aos 36 meses. É também nesta idade que as mães desejam um maior engajamento paterno no estabelecimento de limites. Este é um dos pontos que, segundo a classificação de Muzio (1998), os pais deste estudo mais se distanciam da paternidade tradicional, na qual uma característica marcante seria exatamente o fato de o pai exercer o "poder" dentro da família.

A análise das entrevistas havia sugerido que predominava nos pais participantes a "paternidade com manifestações de mudanças", segundo a classificação de Muzio (1998), o que foi confirmado pelo resultado do Estilo Paterno. Os pais ainda apresentam características da "paternidade tradicional", tais como: preferir se envolver em atividades lúdicas e não apreciar as tarefas de cuidado. Também apresentam características da "paternidade não tradicional": não gostar de impor regras e limites e compartilhar tarefas. 


\section{CONSIDERAÇÕES FINAIS}

A maioria dos pais e mães envolvidos neste estudo percebe diferença na participação paterna ao longo do desenvolvimento. Quanto menor a idade do filho menor é a participação paterna. Ou seja, os cuidados iniciais com o bebê têm pouca participação do pai. Esses resultados podem ser pensados devido aos meses de dedicação exclusiva que a mãe tem com o bebê e até mesmo pelo fato de muitas mulheres afastarem o pai neste momento inicial. Conforme a mulher vai retomando a sua rotina de vida e trabalho, o pai vai ganhando mais espaço para se envolver com o filho.

No que concerne aos aspectos onde a participação paterna é mais ou menos frequente, observamos que os pais preferem o envolvimento com as atividades lúdicas, inclusive sendo este um dos itens de maior satisfação materna em relação ao envolvimento do pai. Os pais demonstram não gostar dos momentos nos quais necessitam impor regras e limites e consideram que o fazem mais vezes do que gostariam. Esta característica afasta esse grupo de pais da paternidade tradicional. Os pais participantes, de uma forma geral, estão satisfeitos com o seu exercício da paternidade, mas consideram que as mães, não só incentivam a sua participação, como desejam um exercício de paternidade mais intenso.

Em síntese, percebe-se atualmente uma tendência em um envolvimento do pai no cotidiano dos filhos, afastando-se de algumas características da paternidade tradicional. Foi possível também verificar em que aspectos a paternidade atual se aproxima ou se afasta da paternidade tradicional, trazendo contribuições importantes em relação à participação paterna. Desta forma, este estudo contribui para a compreensão das novas configurações familiares, assim como os papéis exercidos por seus membros contemporaneamente em famílias ocidentais e urbanas.

\section{REFERÊNCIAS}

Bandeira, T. T. A. (2009). Crenças sobre o investimento parental. Dissertação de mestrado não-publicada, Universidade do Estado do Rio de Janeiro, Rio de Janeiro, RJ.

Bardin, L. (2002). Análise de conteúdo (L. A. Reto \& A. Pinheiro. Trad.). Lisboa: Edições 70.

Bittman, M. (1995). Changes at the heart of family households. Family Matters, 40, 10-15.

Brandth, B., \& Kvande, E. (2002). Reflexive fathers: Negotiating parental leave and working life. Gender, Work and Organization, 9, 186-203.

Burdon, B. (1998). Envolvendo os homens na vida familiar: Se eles podem fazê-lo, por que não o fazem? Em P. Silveira
(Org.), Exercício de paternidade (pp. 81-90). Porto Alegre: Artes Médicas.

Bustamante, V., \& Bonfim, L. A. (2005). Participação paterna no cuidado de crianças pequenas: Um estudo etnográfico com famílias de camadas populares. Cadernos de Saúde Pública, 21, 1865-1874.

Cabrera, N., Tamis-LeMonda, C. S., Bradley, R. H., Hofferth, S., \& Lamb, M. E. (2000). Fatherhood in the twenty-first century. Child Development, 71, 127-136.

Dienhart, A. (2001). Make room for daddy: The pragmatic potentials of a tag-team structure for sharing parenting. Journal of Family Issues, 22, 973-999.

Diniz, G. R. S. (1999). Homens e mulheres frente à interação casamento-trabalho: Aspectos da realidade brasileira. Em T. Féres-Carneiro (Org.), Casal e família: Entre a tradição e a transformação (pp. 31-54). Rio de Janeiro: NAU.

Featherstone, B. (2001). Research review: Putting fathers on the child welfare agenda. Child and Family Social Work, 6, 179186.

Fleck, A., \& Wagner, A. (2003). A mulher como a principal provedora do sustento econômico familiar. Psicologia em Estudo, 8 (número especial), 31-38.

Goetz, R. E., \& Vieira, M. L. (2009). Pai real, pai ideal. Curitiba: Juruá.

Gunter, B. G., \& Gunter, N. C. (1990). Domestic division of labor among working couples: Does androgyny make a difference? Psychology of Women Quartely, 14, 335-370.

Jablonski, B. (1998). Paternidade hoje: Uma metanálise. Em P. Silveira (Org.), Exercício de paternidade (pp. 121-129). Porto Alegre: Artes Médicas.

Jablonski, B. (1999). Identidade masculina e o exercício da paternidade: De onde viemos e para onde vamos. Em T. Feres- Carneiro (Org.), Casal e família: Entre a tradição e a transformação (pp.55-69). Rio de Janeiro: NAU.

Keller, H. (1998). Diferentes caminhos de socialização até a adolescência. Revista Brasileira de Crescimento e Desenvolvimento Humano, 8, 1-14.

Keller, H. (2002). Human parent-child relationships from an evolutionary perspective. American Behavior Scientist, 43, 957969.

Levy-Shiff, R., \& Israelashvili, R. (1998). Antecedents of fathering: Some further exploration. Developmental Psychology, 24, 434-440.

Lightfoot, C., \& Valsiner, J. (1992). Parental belief systems under the influence: Social guidance of the construction of personal cultures. Em I. E. Sigel, A. V. McGillicuddy-DeLisi, \& J. J. Goodnow (Orgs.), Parental belief systems: The psychological consequences for children (pp. 393-413). Hillsdale, NJ: Lawrence Erlbaum.

Muzio, P. A. (1998). Paternidade (ser pai)... Para que serve? Em P. Silveira (Org.), Exercício de paternidade (pp. 165-174). Porto Alegre: Artes Médicas.

Piccinini, C. A., Silva, M. R., Gonçalves, T. R., Lopes, S. R., \& Tudge, J. (2004). O envolvimento paterno durante a gestação. Psicologia: Reflexão e Crítica, 17, 303-314.

Rocha-Coutinho, M. L. (2003). Quando o executivo é uma "dama": A mulher, a carreira, e as relações familiares. Em T. Féres-Carneiro (Org.). Família e casal: Arranjos e demandas contemporâneas (pp. 15-30). Rio de Janeiro: NAU. 
Santos, C. A. (2004). Onde está o papai? A construção da paternidade nas pedagogias culturais. Retirado em 10 de março de 2010, de http://www.aleitamento.com.br

Seabra, K. C. (2007). A paternidade em famílias urbanas: Análise da participação do pai na creche-escola e nos cuidados com o filho. Tese de doutorado não-publicada, Universidade do Estado do Rio de Janeiro, Rio de Janeiro, RJ.

Seabra, K. C., Sivieiro, M., \& Seidl de Moura, M. L (2001). A percepção materna sobre o pai de seus bebês e o pai ideal em mães primíparas de bebês de cinco meses de idade. Trabalho apresentado no II Congresso Norte-Nordeste de Psicologia, Salvador.

Seidl de Moura, M.L. (2009). Interações sociais e desenvolvimento. Em M. L. Seidl de Moura, D. M. L. F. Mendes, \& L. F. Pessoa (Orgs.), Interação social e desenvolvimento (pp.19-36). Curitiba: CRV.

Silva, M. R., \& Piccinini, C. A. (2007). Sentimentos sobre a paternidade e o envolvimento paterno: Um estudo qualitativo. Estudos de Psicologia, 24, 561-573.
Souza, N. H. S., Wagner, A., Branco, B. M., \& Reichert, C. B. (2007). Famílias com casais de dupla carreira e filhos em idade escolar: Estudo de casos. Aletheia, 26, 109-121.

Trindade, Z. A., Andrade, C. A., \& Souza, Q. J. (1997). Papéis parentais e representações da paternidade: A perspectiva do pai. Psico, 28, 207-222.

Wagner, A., Predebon, J., Mosmann, C., \& Verza, F. (2005). Compartilhar tarefas? Papéis e funções de pai e mãe na família contemporânea. Psicologia: Teoria e Pesquisa, 21, 181-186.

Wagner, A., \& Levandowski, D. C. (2008). Sentir-se bem em família: Um desafio frente à diversidade. Textos e Contextos, 7 , 88-97.

Notas:

1 Coordenado por Maria Lucia Seidl de Moura no Programa de Pós-Graduação em Psicologia Social da Universidade do Estado do Rio de Janeiro.

2 Professor da UFRJ e Doutor pelo Programa de Pós-Graduação em Psicologia Social da Universidade do Estado do Rio de Janeiro.

3 Professora aposentada da UERJ e Doutora em Psicologia pelo Programa de Pós-Graduação em Psicologia da UFRJ.

4 Realizado pelo grupo Interação Social e Desenvolvimento, coordenado por Maria Lucia Seidl de Moura no Programa de Pós-Graduação em Psicologia Social da Universidade do Estado do Rio de Janeiro. 